\title{
Study on Synthesis and Service Properties of Anticoagulant Ice Microcapsule Coating Material
}

\author{
Rong Chang $\mathbb{D}^{1,2}$, Jie Wang $\mathbb{D}^{1},{ }^{1}$ Yongchun Qin, ${ }^{1}$ Jian $\mathrm{Xu},{ }^{1}$ Wei Zeng, \\ Yange Zhang, ${ }^{1}$ and Peng Wang ${ }^{1}$ \\ ${ }^{1}$ Research Institute of Highway, Ministry of Transport, Beijing 100088, China \\ ${ }^{2}$ Key Laboratory for Special Area Highway Engineering of Ministry of Education, Chang'an University, Xi'an, \\ Shaanxi 710064, China \\ Correspondence should be addressed to Jie Wang; j.wang@rioh.cn
}

Received 11 May 2021; Accepted 1 September 2021; Published 17 September 2021

Academic Editor: Guosong Wu

Copyright (C) 2021 Rong Chang et al. This is an open access article distributed under the Creative Commons Attribution License, which permits unrestricted use, distribution, and reproduction in any medium, provided the original work is properly cited.

The presence of ice and snow on a road surface in winter will reduce the traffic capacity of the road network, which can easily lead to traffic accidents. In this study, nonchlorine organic snow-melting salt was added to emulsified asphalt to prepare an anticoagulant ice fog seal. Considering the destructive effect of snow-melting salt on the stability of emulsified asphalt, polyvinyl alcohol was used as an encapsulation material to form a stable two-phase system by mixing snow-melting salt with emulsified asphalt. The zeta potential method was used to test the storage stability of the encapsulated salt solution. The results showed that the material and content of the encapsulation had a significant effect on the stability of the emulsified asphalt and the reduction in the freezing point of the encapsulated salt solution. PVA (1.5\%) mixed with $24 \%$ sodium acetate was used to prepare an encapsulated salt emulsion, which was mixed with anionic emulsified asphalt and sprayed on the road surface. This significantly reduced the freezing point of road surface water. The recommended spraying dosage of the anticoagulant ice fog seal layer was $0.4 \mathrm{~kg} / \mathrm{m}^{2}$, which could lower the freezing point by at least $-8^{\circ} \mathrm{C}$ while simultaneously meeting the antislip performance condition. This was shown to be a preventive maintenance technology with both anticoagulant ice and maintenance effects.

\section{Introduction}

At the beginning or end of winter, any snow on the road gradually melts under the action of the traffic load, which can easily form a thin layer of ice when the temperature is below freezing. The presence of ice and snow on a road surface will reduce the traffic capacity of the road network, and cars will be prone to skidding, which is particularly detrimental to the driving dynamics and safety of vehicles [1]. The current methods for removing ice and snow from roads can be divided into two categories: external technology (passive snow removal) and internal technology (active snow removal) [2]. The methods included in the external technology category mainly involve spraying snow-melting agents and manual and mechanical removal. Those included in the internal technology category mainly include geothermal and solar thermal ice-melting technology and physical and chemical ice and snow suppression technology [3].

Mechanical snow removal cannot completely remove all of the snow. At the same time, it causes a certain amount of damage to the road surface, and there are often problems with insufficient personnel and machinery $[4,5]$. Snowmelting agents are widely used because of their high efficiency, low price, and easy availability [6]. However, the use of snow-melting agents has seriously impacted the environment alongside highways, mainly by causing the largescale destruction of green vegetation and severe corrosion of the reinforced concrete in roads and bridges [7]. In addition, snow-melting agents can also affect the properties of the soil and water bodies [8].

The commonly used chemical snow-melting agents are mainly divided into three types: chloride, nonchlorine, and mixed [9]. Inorganic chloride salts with sodium chloride, 
calcium chloride, potassium chloride, and magnesium chloride as the main components are called chloride salttype snow-melting agents, whereas organic snow-melting agents with potassium acetate and other organic substances as the main components are collectively called nonchloridetype snow-melting agents. This type of snow-melting agent mainly consists of salts, amines, and alcohols. Based on the material form of the salt, the salts can be divided into the aggregate, filler, and paint types. In the first two, the salt compound is prepared as coarse particles or a fine powder and used to replace part of the fine aggregate or mineral powder in the asphalt mixture. In the third type, the salt is prepared as an emulsion to be sprayed on the road surface and is often used for short-term salt storage. To increase the slow release effect, the salt material usually requires inclusions. The inclusion materials can be divided into the oleoresin type, inorganic cement type, and porous carrier type $[10,11]$. (1) The earliest examples of the oleoresin type are the use of fats and oils, such as linseed oil as coating materials for salt [12]. Later, the use of various resins and water repellents gradually developed $[13,14]$. (2) Powder sintering, gel material cementation, and other methods are used for the inorganic cement type $[15,16]$, where the snowmelting components are consolidated inside the particles, and even the salt-containing gelling material itself can be used as a salt storage structure [17]. (3) In the porous carrier type, porous structures, such as volcanic rock or zeolite materials $[18,19]$, are mainly used to load snow-melting components. Paint-type salts usually use various emulsions as carriers to prepare salt storage emulsions. Direct spraying in new construction, reconstruction, expansion, and even existing roads can be used for the short-term functions of salt storage and snow melting. A salt storage emulsion can be used for road spraying, as well as a slurry seal, fog seal, and so on $[20,21]$. In addition, the adsorption of a snow-melting salt in the prefabricated porous structure of a road or bridge deck can also perform the functions of short-term salt storage, snow-melting, and ice suppression [22].

The long-term anti-icing effect of salt-storing asphalt pavement and the effect of snow-melting salt on the performance of asphalt mixtures need to be verified. In addition, the removal of ice and snow is a seasonal requirement, and high temperatures and rain in summer cause a salt loss in salt-storing asphalt pavements [23].

Paint-type salt can be used for the preventive maintenance of roads, with convenient and simple construction and high flexibility. Some road sections prone to freezing can be sprayed in an emergency based on the weather forecast. The amount of snow-melting agent can be designed based on the climatic conditions of a specific section and region [24]. In this study, a preventive maintenance emulsion with an anti-icing function was prepared by adding a nonchloride salt to the emulsified asphalt. The stability of the emulsified asphalt was greatly reduced by the addition of salt electrolyte materials. According to the Stern electric double layer theory, the mutual repulsive force between the asphalt particles in emulsified asphalt can only be thermodynamically balanced by offsetting the collision and gravity settlement caused by Brownian motion [25]. The repulsive force of asphalt particles mainly comes from two aspects: the electric double layer around the particles and the interaction between the nonionic substances adsorbed on the surfaces of the particles. The electric double layer consists of two parts. The particles distributed on the surface of the asphalt particles are called positioning ions, which constitute the inner layer; the opposite ions attracted to the outside of the particles are called counterions, which constitute the diffusion layer. A schematic diagram of a bitumen particle electric double layer is shown in Figure 1.

Ionic emulsified asphalt particles have polar charges on their surfaces, and their microstructures follow the electric double-layer model. The zeta potential is generally used as a measure of the electric double layer. According to thermodynamic theory, the zeta potential of the emulsion affects the storage stability of the emulsified asphalt. The zeta potential value is only related to the activity of the ions adsorbed by the asphalt particles in the solution [27]. In the electric double layer, the potentials at different distances from the surfaces of the asphalt particles are also different, as shown in Figure 2. If it is supposed that the concentrations of positive and negative ions at $\mathrm{CD}$ are equal, the potential is zero. When a certain amount of charge is adsorbed on the surfaces of the asphalt particles, the potential difference relative to $\mathrm{CD}$ is $\psi$ (i.e., the thermodynamic potential). When the particles are affected by an external electric field and move along the $A B$ surface, a potential difference is generated, which is called the electrokinetic potential ( $\zeta$ electric potential) $[28,29]$. As shown in Figure 2, the thickness of the diffusion layer determines the size of the potential, with a thinner diffusion layer resulting in a smaller electrokinetic potential. When the diffusion layer overlaps $\mathrm{CD}$, the electrokinetic potential is zero.

Using the $\zeta$ electric potential test method, suitable polymer materials were selected for the interface film to wrap the snow-melting salt and form a microencapsulated structure [30]. After mixing with the emulsified asphalt, the two phases reached thermodynamic equilibrium and formed a stable emulsified asphalt-based snow-melting stock solution [31]. Before spraying on the road surface, a fog seal layer was formed. A pull-out test and simulated freezing test were used to evaluate the anti-icing performance of the fog seal. The emulsified asphalt in the anti-icing fog seal layer slowly released the nonchlorinated snow-melting salt after demulsification. In a low-temperature environment in the winter, this can reduce the freezing point of the road surface water and make the road less icy. When extreme icy and snowy weather occurs, it can also achieve good deicing and snow removal effects when combined with other external technologies.

\section{Experimental Design}

\subsection{Materials}

2.1.1. Asphalt. Asphalt materials mainly play a cohesive role during use. Asphalt with high penetration is easier to emulsify than asphalt with low penetration. Therefore, high penetration asphalt or wax-free base asphalt should be 


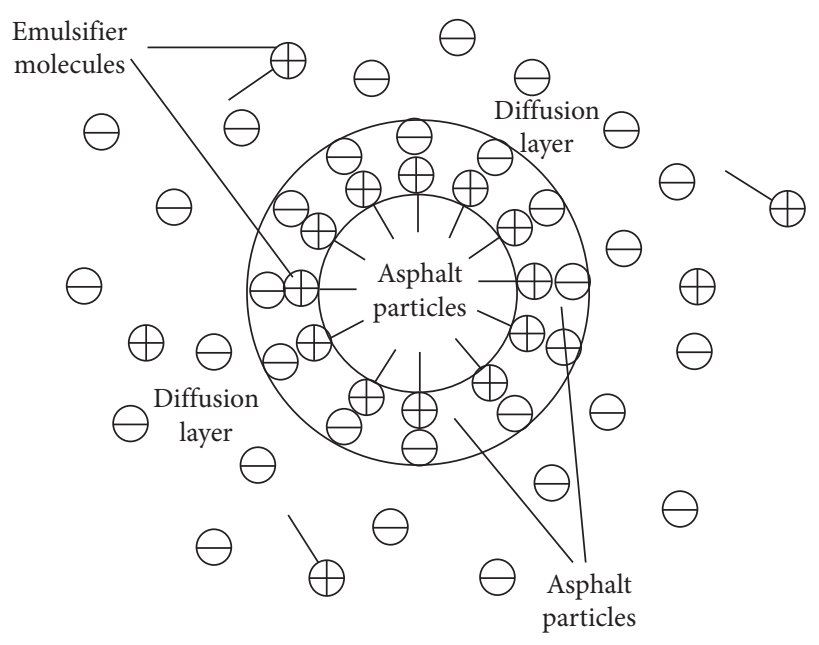

FIgURE 1: Schematic diagram of the electric double layer of the asphalt particle [26].

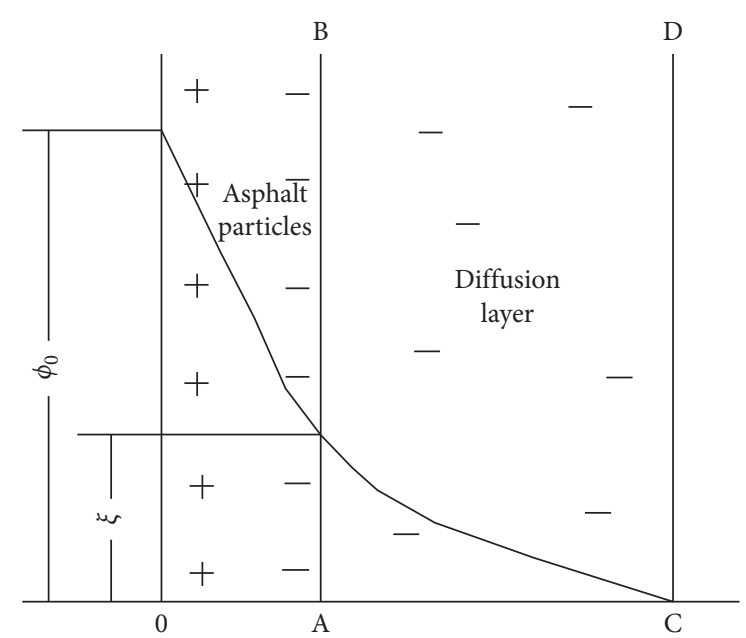

FIgURE 2: Schematic diagram of emulsified asphalt zeta potential [27].

selected as much as possible. In this study, road asphalt No. 90 A grade was selected for the experiment. The basic properties of grade $90 \mathrm{~A}$ road asphalt are listed in Table 1.

2.1.2. Emulsifier. A cationic quick-cracking emulsifier and an anionic emulsifier were adopted.

The effects of different emulsifier dosages on the stability of the asphalt emulsions were tested (Tables 2 and 3). The emulsifier adopts cationic quick-cracking emulsifier and anionic emulsifier, respectively. When the amount of emulsifier is small, the asphalt cannot be fully emulsified; when the amount of emulsifier is large, the fluidity of the emulsified asphalt is enhanced and the flow rate is faster, so the appropriate amount of emulsifier should be selected. The table shows that different ionic emulsifiers have the same influence on the storage stability (5d) of emulsified asphalt, and the change trend of the absolute value of the zeta potential is also the same.
The stability of emulsified asphalt increases with the amount of emulsifier, and the continuous phase viscosity of the asphalt emulsion continues to increase. The storage stability of emulsified asphalt is basically the same as the absolute value of the zeta potential. Therefore, the absolute value of the zeta potential could be used to evaluate the stability of the emulsified asphalt. Considering the stability and cost of the emulsion, the dosage of the cationic emulsifier was $1.5 \%$, and the dosage of the anionic emulsifier was $2.8 \%$.

2.1.3. Polymer Encapsulation. In this study, three polymer encapsulation materials were selected: agar, carboxymethyl cellulose, and polyvinyl alcohol. The agar solution is a colorless, transparent, and viscous liquid. It can form a layer of hydration film on the surface of the asphalt particles when added to the asphalt solution. It has the functions of thickening, stabilizing, and dispersing the emulsified asphalt [32].

After the sodium carboxymethyl cellulose is added to the pitch, the molecules are cross-linked together, and the snowmelting salt is wrapped in the solution to increase the viscosity of the capsule salt emulsion. After being mixed with emulsified asphalt, it can protect the asphalt particles in the emulsion from being affected by external conditions and demulsify so that the storage stability of the snow-melting agent is improved [26].

Polyvinyl alcohol is a macromolecular compound that can protect asphalt particles and help asphalt emulsification. However, if the amount is too large, the extensibility of the asphalt will be reduced [33].

2.1.4. Stabilizing Agent. The stabilizing agent was polyacrylamide, which is a white powder with a solid content of $\geq 88 \%$ and cation concentration of $10-60 \%$ based on test. Polyacrylamide can increase the consistency of the water phase, decrease the density difference between the oil and water phases, and form a dense interfacial film on the surface of asphalt particles. It can slow down the collision strength of dispersed asphalt particles and prevent coalescence or precipitation. The influence of the stabilizer dosage on the stability of the emulsified asphalt is shown in Figures 3 and 4.

With the increase of the amount of stabilizer, the stability of emulsified asphalt with different ions increases, but when the amount exceeds $0.8 \%$, the $5 \mathrm{~d}$ storage stability of the emulsified asphalt cannot be significantly improved. Based on economic considerations, the stabilizer is the best. The dosage is $0.8 \%$.

2.1.5. Nonchloride Snow-Melting Salt. The nonchlorinated snow-melting salt contained sodium acetate and magnesium acetate.

\subsection{Experimental Methods}

2.2.1. Bond Strength Test. In extreme snowy and icy weather, rain and snow condense into ice on a road surface, greatly 
TABle 1: Properties of no. 90 A asphalt.

\begin{tabular}{|c|c|c|c|c|}
\hline Items & Unit & Skill requirement & Test results & Experiment method \\
\hline Penetration $100 \mathrm{~g}, 5 \mathrm{~s}, 25^{\circ} \mathrm{C}$ & $0.1 \mathrm{~mm}$ & $80 \sim 100$ & 86 & T0604 \\
\hline Softening point $T_{\mathrm{R} \& \mathrm{~B}}$ & ${ }^{\circ} \mathrm{C}$ & $\geq 45$ & 46.5 & T0606 \\
\hline Dynamic viscosity $60^{\circ} \mathrm{C}$ & $\mathrm{Pa} \cdot \mathrm{s}$ & $\geq 160$ & 187.1 & T0620 \\
\hline Ductility $5 \mathrm{~cm} / \mathrm{min}, 10^{\circ} \mathrm{C}$ & $\mathrm{cm}$ & $\geq 45$ & $>100$ & T0605 \\
\hline Ductility $5 \mathrm{~cm} / \mathrm{min}, 15^{\circ} \mathrm{C}$ & $\mathrm{cm}$ & $\geq 100$ & $>100$ & T0605 \\
\hline Wax content (distillation method) & $\%$ & $\leq 2.2$ & 1.7 & T0615 \\
\hline Flash point (COC) & ${ }^{\circ} \mathrm{C}$ & $\geq 245$ & 264 & T0611 \\
\hline Solubility (trichloroethylene) & $\%$ & $\geq 99.5$ & 99.72 & T0607 \\
\hline Density, $15^{\circ} \mathrm{C}$ & $\mathrm{g} / \mathrm{cm}^{3}$ & Measured record & 1.028 & T0603 \\
\hline \multirow{3}{*}{$\begin{array}{l}\text { Residual penetration ratio } \\
\text { Residual ductility, } 10^{\circ} \mathrm{C}\end{array}$} & $\%$ & $\leq \pm 0.8$ & -0.158 & T0609 \\
\hline & $\%$ & $\geq 57$ & 66.2 & T0604 \\
\hline & $\mathrm{cm}$ & $\geq 8$ & 14 & T0605 \\
\hline
\end{tabular}

TABLE 2: Effect of cationic emulsifier dosage on emulsion performance.

\begin{tabular}{lccc}
\hline Emulsifier dosage (\%) & The remaining amount on the sieve (\%) & 5d storage stability (\%) & Zeta potential value (mV) \\
\hline 1.1 & 0.215 & 6.12 & 16.7 \\
1.3 & 0.117 & 3.58 & 20.8 \\
1.5 & 0.046 & 2.42 & 22.1 \\
1.7 & 0.037 & 2.01 & 32.4 \\
\hline
\end{tabular}

TABLE 3: Influence of the amount of the anionic emulsifier on the performance of emulsion.

\begin{tabular}{lccc}
\hline Emulsifier dosage (\%) & The remaining amount on the sieve (\%) & 5d storage stability (\%) & Zeta potential value (mV) \\
\hline 2.0 & 0.38 & 9.64 & 12.3 \\
2.2 & 0.23 & 8.75 & 16.4 \\
2.4 & 0.16 & 6.25 & 28.6 \\
2.6 & 0.09 & 5.33 & 32.3 \\
2.8 & 0.07 & 4.21 & 48.3 \\
3.0 & 0.03 & 3.36 & 51.2 \\
3.2 & 0.02 & 3.23 & 53.6 \\
\hline
\end{tabular}

reducing its antiskid performance. At present, there is no comprehensive method for quantitatively characterizing the bonding strength of ice and roads. Therefore, this study designed and developed a "road surface ice and snow bonding strength test device" to test the bonding strength between the fog seal layer and the ice surface. This device is shown in Figure 5. The device could quantitatively evaluate the freezing point and its effect on melting snow and ice.

The road surface ice and snow bond strength test included the following steps:

(1) Two sets of asphalt mixture test pieces $(300 \times 300 \times 50 \mathrm{~mm})$ were obtained, with a sprayed anticondensation ice fog sealing layer on the surface of one set of test pieces.

(2) A thin coating of epoxy resin adhesive was applied to the drawing indenter, and a nonwoven piece of fabric with a thickness of $5 \mathrm{~mm}$ was glued to the drawing indenter. The curing time of the adhesive was less than $30 \mathrm{~min}$.

(3) The drawing indenter was immersed in water to saturate the nonwoven fabric with water and then placed on the surface of the asphalt mixture sample.
They were then kept in a low-temperature environment at $-4^{\circ} \mathrm{C}$ for $4 \mathrm{~h}$.

(4) At the set test temperature, the drawing test was carried out at a constant speed of $5 \mathrm{~mm} / \mathrm{min}$ to determine the breaking tensile force when the surface of the asphalt mixture specimen was separated from the drawing indenter, and the bond strength was calculated according to the following formula:

$$
S=\frac{F}{A_{e}},
$$

where $S$ is the bond strength (MPa), $F$ is the breaking force $(\mathrm{N})$, and $A_{e}$ is the effective contact area between the anticondensation ice fog sealing layer and nonwoven fabric $\left(\mathrm{mm}^{2}\right)$.

2.2.2. Simulated Freezing Test. After the anticondensation ice fog seal layer is demulsified under the action of the atmosphere and driving, the salt that continuously precipitates from the cyst combines with the road surface water, 


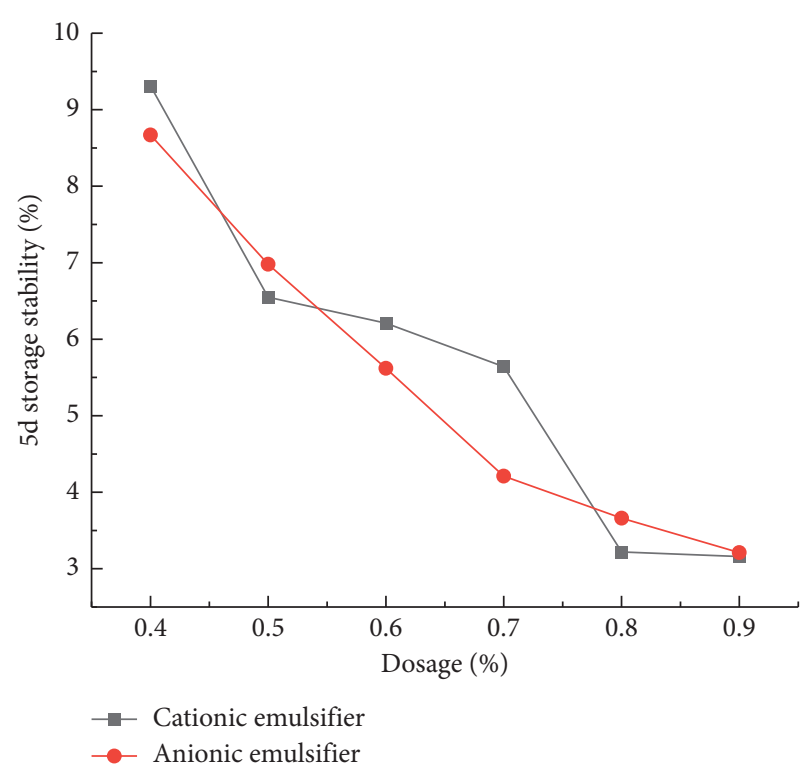

FIgURE 3: The effect of stabilizer dosage on $5 \mathrm{~d}$ storage stability.

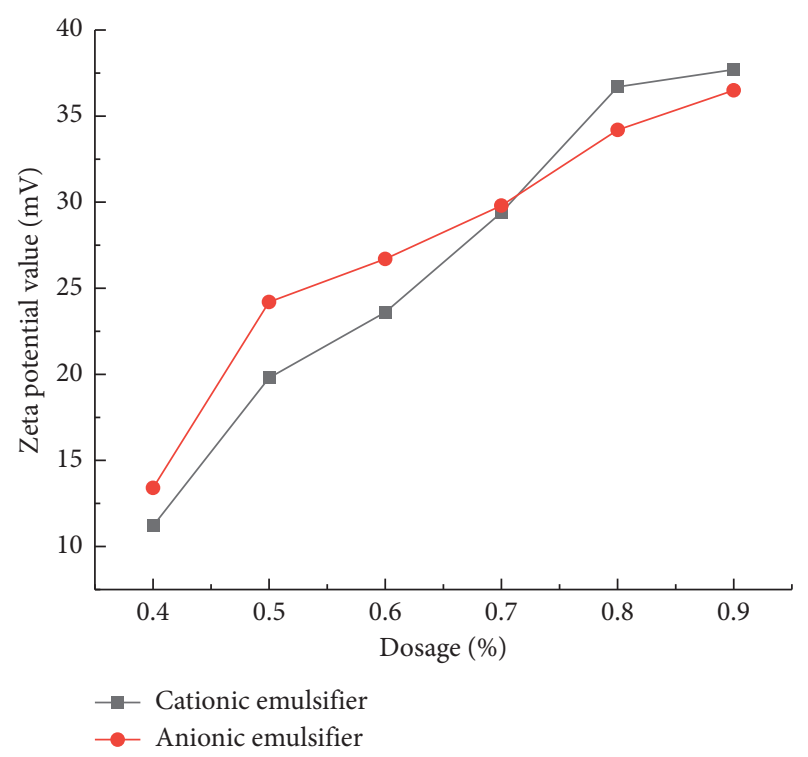

Figure 4: The effect of stabilizer dosage on the zeta potential value.

where it reduces the vapor pressure of the water to achieve the effect of reducing the freezing point. When its freezing point is lower than the ambient temperature, snow will change from the solid phase to the liquid phase and will exist as muddy salt water on the road surface. This state will keep ice and snow from freezing for a long time. The test method tested the freezing and slow release effects of the self-melting ice fog seal layer by simulating the freezing and thawing of road surface water. The test steps were as follows:

(1) Pour $20 \mathrm{~mL}$ of the encapsulated salt emulsion (about $1.5 \mathrm{~mm}$ in thickness) into a Petri dish and allow it to solidify at rest

(2) Add water to a thickness of approximately $5 \mathrm{~mm}$ to the surface of the completely solidified seal layer
(3) Place the Petri dish in a low-temperature environment and observe the freezing temperature of the free water on the fog seal layer as the temperature decreases to $-4^{\circ} \mathrm{C}$ and $-5^{\circ} \mathrm{C}$, with an observation time interval of $10 \mathrm{~min}$

(4) Finally, melt the frozen ice shell on the surface of the seal layer and replace it with pure water to repeat the freezing and thawing cycle to test the slow release effect of the anticoagulation ice fog seal layer

2.2.3. Skid Resistance Test. A laboratory sand patch test was used to measure the structural depth (TD) of the anticondensation ice fog seal layer and to test the attenuation of the structural depth before and after spraying the anticondensation ice fog seal layer.

2.2.4. Antiwear Performance Test. The anti-icing fog seal layer is sprayed on the road surface before snowfall in winter and is subject to the combined actions of cars and rain, which easily causes abrasion and reduces the snow-melting effect. Therefore, a wet wheel abrasion tester was used to study the abrasion resistance of the anti-icing fog seal layer.

\section{Preparation of the Anticondensation Ice Fog Seal Layer}

3.1. Preparation of Emulsified Asphalt. The oil-water ratio of the emulsified asphalt used in the fog seal in this study consisted of $55 \%$ asphalt and $45 \%$ water, and the colloidal mill speed was approximately $2870 \mathrm{r} / \mathrm{min}$. The amount of cationic emulsifier was $1.5 \%$, and the amount of anionic emulsifier was $2.8 \%$.

First, the emulsifier and stabilizer were dissolved and mixed in water at approximately $70^{\circ} \mathrm{C}$ and added to the colloid mill for shearing for $3 \mathrm{~min}$. Then, the base pitch was heated to $130^{\circ} \mathrm{C}$. The results of the related performance tests of the prepared emulsified asphalt are listed in Table 4. The performance of asphalt emulsions prepared by different ionic emulsifiers has little difference, and the prepared asphalt emulsions have good stability. All indexes of emulsified asphalt meet the inspection standards of emulsified asphalt in the petroleum industry. At the same time, the emulsifier improves the original performance of the asphalt after the emulsion is demulsified.

3.2. Preparation of Encapsulated Salt Emulsion. In this study, the effect of melting snow and ice was achieved by adding a nonchlorinated snow-melting salt to the emulsified asphalt. However, when a large amount of a salt electrolyte is added to emulsified asphalt, the demulsification speed of the emulsion is accelerated. Therefore, a type of encapsulated emulsion was prepared, and a high-molecular-weight polymer was used to wrap around the salt to form an encapsulated structure and then mixed with the emulsified asphalt so that the two-phase system could exist stably. 


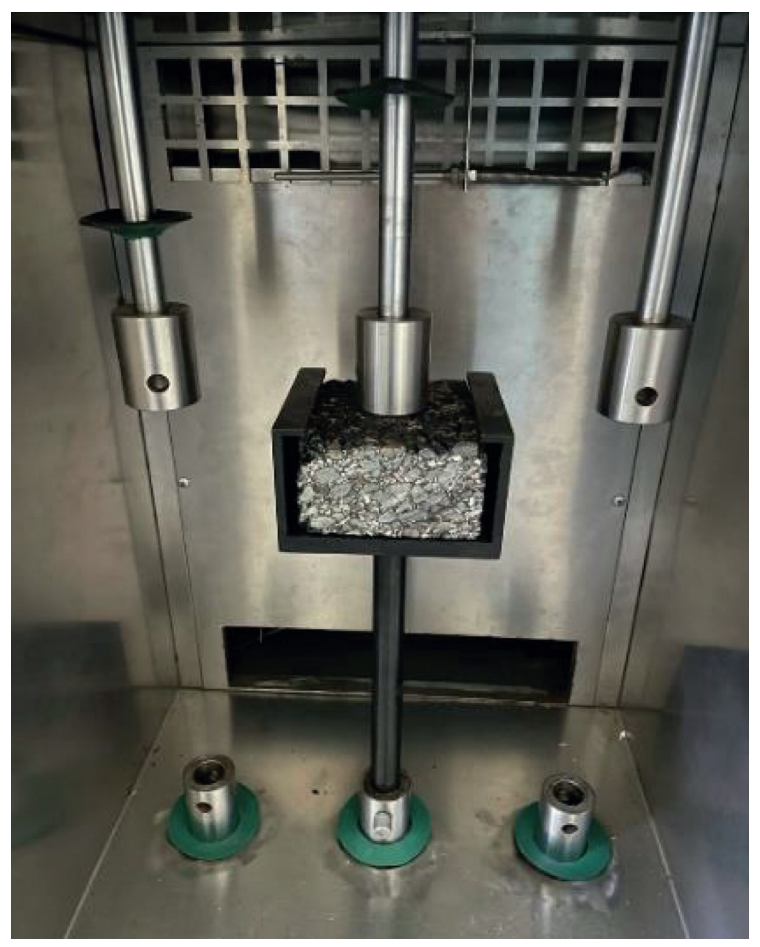

Figure 5: Bond strength test device.

The compatibility design of the encapsulated salt emulsion was based on the relationship between the freezing point depression value and solute molar concentration:

$$
\Delta T_{f}=k_{f} \times m,
$$

where $\Delta T_{f}$ is the freezing point drop $\left({ }^{\circ} \mathrm{C}\right), k_{f}$ is the molar freezing point drop constant of the solvent $\left(\mathrm{k} \cdot \mathrm{kg} \cdot \mathrm{mol}^{-1}\right)$, and $m$ is the molarity of the solution $(\mathrm{mol} / \mathrm{kg})$.

Nonchloride salts are generally divided into two types: $\mathrm{AB}$ and $\mathrm{AB}_{2}$. Water was used as the solvent, which has a $K_{\mathrm{f}}$ value of $1.86 \mathrm{~K} \mathrm{~kg} \mathrm{~mol}^{-1}$. For the $\mathrm{AB}$ type strong electrolyte, $2 \mathrm{~mol}$ of ions was completely ionized in water, and the $K_{\mathrm{f}}$ value was $3.72 \mathrm{~K} \mathrm{~kg} \mathrm{~mol}^{-1}$. For the $\mathrm{AB}_{2}$ type of strong electrolyte, $3 \mathrm{~mol}$ of ions was completely ionized in water, and the $K_{\mathrm{f}}$ value was $5.58 \mathrm{~K} \mathrm{~kg} \mathrm{~mol}^{-1}$. In the preliminary plan to reduce the freezing point to $-8^{\circ} \mathrm{C}, \Delta T_{f}$ was $8 \mathrm{~K}$.

According to formula (2), when the freezing point drops to $-8^{\circ} \mathrm{C}$, the $K_{f}$ value of sodium acetate is 3.72 , the molecular weight is 82.03 , and the dosage is $17.6 \mathrm{~g}$; the $K_{f}$ value of magnesium acetate is 5.58, the molecular weight is 214.46, and the dosage is $30.7 \mathrm{~g}$. In laboratory tests, it was found that when the sodium acetate content exceeded $6 \mathrm{~g}$ and the magnesium acetate content exceeded $9 \mathrm{~g}$, the emulsified asphalt was demulsified. Therefore, the emulsification effect of the emulsified asphalt was protected by adding a highmolecular-weight polymer to wrap the snow-melting salt and form a capsule structure.

In this study, agar, carboxymethyl cellulose, and polyvinyl alcohol were selected as the encapsulation materials. The stability results obtained using $1.5 \%$ encapsulation + snow-melting salt mixed with emulsified asphalt are listed in Table 5. Polyvinyl alcohol was selected as the encapsulation material based on the compatibility of the encapsulated salt emulsion.

It can be seen that the combinations of the cationic emulsified asphalt with magnesium acetate and the anionic emulsified asphalt with sodium acetate had better uniformity and storage stability. The structure of the encapsulated salt emulsion was observed using a fluorescence microscope, as shown in Figure 6. The microcapsule-encapsulated salt could exist stably in the emulsified asphalt. It was evenly distributed and remained intact. The anionic encapsulated salt solution had good stability, and the demulsification time could be as long as 30 days or more. Encapsulated salt emulsions can be used during the construction period in practical engineering.

After the encapsulated salt emulsion was prepared, it was stored in a closed vertical tank at room temperature, and the emulsified asphalt was properly stirred during storage. There should be no segregation, no freezing, and no demulsification during the storage period.

\section{Results and Discussion}

4.1. Bond Strength Test. In this test, $0.4 \mathrm{~L} / \mathrm{m}^{2}$ was applied to the asphalt mixture sample, and the bond strength results at different drawing rates at $-8^{\circ} \mathrm{C}$ are listed in Table 6 .

It can be seen from Table 6 that the use of a constant drawing speed of $5 \mathrm{~mm} / \mathrm{min}$ provided better control in the test, with less data deviation and more accurate results. Therefore, the drawing rate of the drawing tester was adjusted to $5 \mathrm{~mm} / \mathrm{min}$, and the breaking strength was measured at different spray rates at $-6^{\circ} \mathrm{C},-8^{\circ} \mathrm{C},-10^{\circ} \mathrm{C},-12^{\circ} \mathrm{C}$, and $-14^{\circ} \mathrm{C}$. The bond strength results were calculated, as shown in Table 7 and Figure 7.

With the increase of spraying amount, the bond strength at each temperature decreased, and the bond strength was even zero at high temperature. This is because the anticondensable ice fog seal can reduce the freezing point of the pavement so that it does not freeze or reduce the degree of freezing at lower temperature. When the temperature was higher than $-12^{\circ} \mathrm{C}$, the bond strength was about $0 \sim 0.2 \mathrm{MPa}$ and test results of Meng's research were 0.11 0.32 MPa [34], which was close to the results obtained in this paper, but the literature did not specify the test temperature. The test results show that a pull-out tester could be used to quantitatively characterize the anti-ice-condensation effect of the fog seal layer.

4.2. Simulated Freezing Test. A road surface is constantly subjected to repeated freeze-thaw cycles, alternating between dry and wet states. Considering practical engineering applications, the repeated rolling contact with vehicle tires and the scouring effect during rainfall will produce a great degree of wear on the snowmelt seal. This will cause the salt content in the seal to continue to decrease, which will decrease the reduction effect on the freezing point until it disappears. In this study, the frozen ice crust on the surface of the sealing layer was thawed and replaced with pure water for repeated freezing and thawing, and the performances of antifreezing 
TABLE 4: Technical indices of emulsified asphalt.

\begin{tabular}{|c|c|c|c|c|c|c|}
\hline \multirow{2}{*}{\multicolumn{2}{|c|}{$\frac{\text { Test item }}{\text { Particle charge }}$}} & \multicolumn{2}{|c|}{ Test results } & \multicolumn{2}{|c|}{ Technical standard } & \multirow{2}{*}{$\frac{\text { Experiment method }}{\text { T0653 }}$} \\
\hline & & Cation & Anion & Cation & Anion & \\
\hline Demulsification spe & & Rapid rupture & Slow rupture & Rapid rupture & Slow rupture & T0658 \\
\hline The remaining amo & ant on the sieve $(1.18 \mathrm{~mm})(\%)$ & 0.05 & 0.03 & $\leq 0.1$ & $\leq 0.1$ & T0652 \\
\hline $5 \mathrm{~d}$ storage stability & & 3.39 & 3.76 & $\leq 5$ & $\leq 5$ & T0655 \\
\hline Standard viscosity o & fasphalt $\mathrm{C}_{25,3}(\mathrm{~s})$ & 18 & 20 & $10-25$ & $8-20$ & T0621 \\
\hline Evaporation residue & content $(\%)$ & 58 & 59 & $\geq 50$ & $\geq 50$ & T0651 \\
\hline \multirow{4}{*}{ Evaporation residue } & Ductility $\left(15^{\circ} \mathrm{C}\right)(\mathrm{cm})$ & 58.2 & 77.4 & 40 & 40 & T0605 \\
\hline & Penetration $\left(25^{\circ} \mathrm{C}\right)(0.1 \mathrm{~mm})$ & 71.6 & 76.2 & $50-200$ & $50-300$ & T0604 \\
\hline & Softening point $\left({ }^{\circ} \mathrm{C}\right)$ & 50.7 & 50.4 & $\geq 50$ & $\geq 50$ & T0606 \\
\hline & Solubility (trichloroethylene) (\%) & 98.6 & 59.2 & $\geq 97.5$ & $\geq 97.5$ & T0607 \\
\hline
\end{tabular}

Table 5: Different effects on emulsion performance.

\begin{tabular}{|c|c|c|c|c|}
\hline Emulsified asphalt & Cyst species & Snow-melting salt & 5 d storage stability (\%) & Zeta potential value $(\mathrm{mV})$ \\
\hline \multirow{6}{*}{ Cationic emulsifier } & \multirow{2}{*}{ Agar } & Sodium acetate & 8.66 & 16.3 \\
\hline & & Magnesium acetate & 9.57 & 11.5 \\
\hline & \multirow{2}{*}{ Carboxymethyl cellulose } & Sodium acetate & 5.17 & 21.5 \\
\hline & & Magnesium acetate & 2.36 & 42.6 \\
\hline & \multirow{2}{*}{ Polyvinyl alcohol } & Sodium acetate & 3.62 & 27.6 \\
\hline & & Magnesium acetate & 3.33 & 24.5 \\
\hline \multirow{6}{*}{ Anionic emulsifier } & \multirow{2}{*}{ Agar } & Sodium acetate & 7.65 & 17.4 \\
\hline & & Magnesium acetate & 8.93 & 14.2 \\
\hline & \multirow{2}{*}{ Carboxymethyl cellulose } & Sodium acetate & 4.66 & 31.6 \\
\hline & & Magnesium acetate & 4.53 & 29.6 \\
\hline & \multirow{2}{*}{ Polyvinyl alcohol } & Sodium acetate & 1.15 & 61.7 \\
\hline & & Magnesium acetate & 2.65 & 39.4 \\
\hline
\end{tabular}

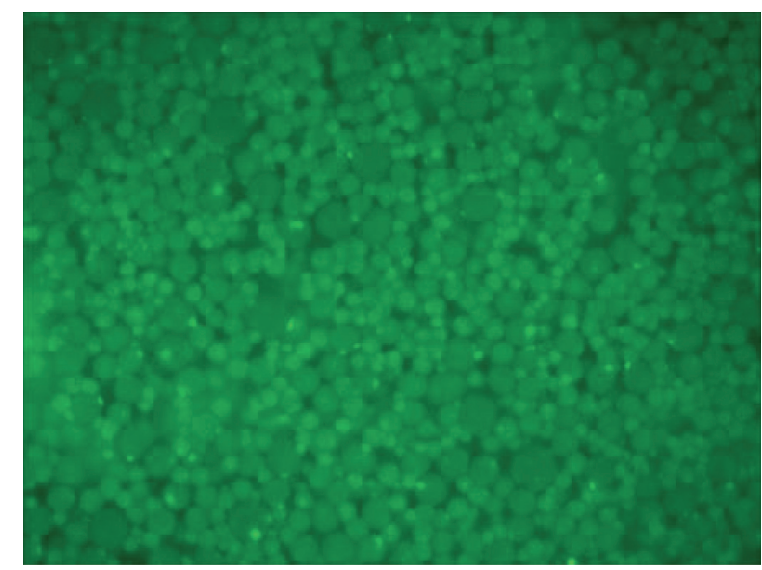

FIgURE 6: Micrograph of encapsulated salt emulsion.

TABLE 6: Bond strength results under different drawing rates.

\begin{tabular}{|c|c|c|c|c|}
\hline \multirow{2}{*}{ Constant speed specimen } & \multicolumn{4}{|c|}{ Bond strength $(\mathrm{MPa})$} \\
\hline & $20 \mathrm{~mm} / \mathrm{min}$ & $15 \mathrm{~mm} / \mathrm{min}$ & $10 \mathrm{~mm} / \mathrm{min}$ & $5 \mathrm{~mm} / \mathrm{min}$ \\
\hline \multirow{2}{*}{ Cationic emulsified asphalt test piece } & 0.16 & 0.31 & 0.21 & 0.11 \\
\hline & 1.27 & 0.88 & 0.66 & 0.12 \\
\hline Electrode difference & 1.11 & 0.57 & 0.45 & 0.01 \\
\hline \multirow{2}{*}{ Anionic emulsified asphalt test piece } & 0.05 & 0.03 & 0.03 & 0.04 \\
\hline & 0.66 & 0.25 & 0.14 & 0.06 \\
\hline Electrode difference & 0.61 & 0.22 & 0.11 & 0.02 \\
\hline
\end{tabular}




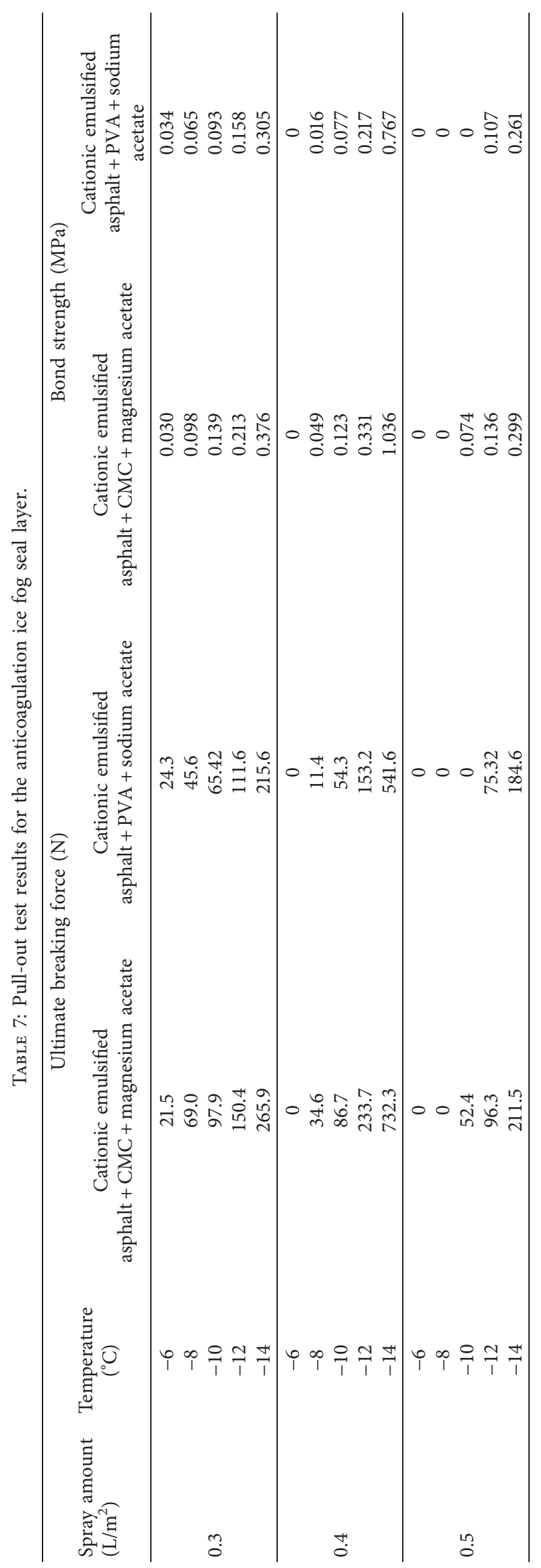




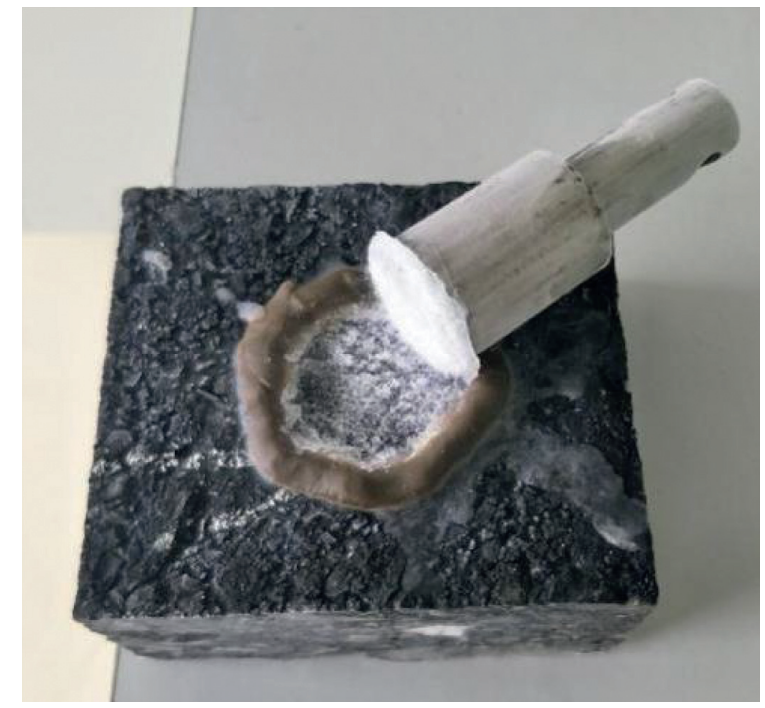

Figure 7: Pull-out test to determine tensile force at failure.

fog seal layers with different concentrations were tested under repeated freezing and thawing conditions. Emulsified bitumen and encapsulated salt emulsion ratios of $2: 1,1: 1$, $1: 2$, and $1: 3$ were tested (the snow-melting salt concentrations were $8 \%, 12 \%, 16 \%$, and $18 \%$, respectively), and the freezing point values after various freeze-thaw cycles are listed in Table 8.

The freezing point of the anticondensation fog seal layer decreased as the number of repeated freezing and thawing cycles increased, and the ability to melt snow and ice gradually weakened. In the fourth freezing test, the freezing point could still be lowered to $-3^{\circ} \mathrm{C}$ when the snow-melting salt concentration was $18 \%$.

The encapsulation technology encapsulated the snowmelting salt to maintain the stability of the two-phase system of nonchloride salt and emulsified asphalt. It could significantly improve the solubility of the salt compounds in the emulsified asphalt without demulsification and surface salt precipitation and could significantly reduce the freezing point of road surface water. It provided a slow release on the road surface for a long time. With the continuous loss of the heat and dissolution heat of the system, the anticondensation ice fog seal layer could still make the water crystals on the road surface loose and fragile. Therefore, under a paved road condition, a loose ice layer would be easily crushed and broken by passing vehicles and would melt without producing a hard layer of ice adhering to the road surface.

Asphalt pavement with Mafilon material can reduce the pavement freezing point to $-10^{\circ} \mathrm{C}$ [35]. Zhao et al. [36] prepared sodium chloride slow-release snow-melting agent, which can reduce the freezing point of water to $-6.04^{\circ} \mathrm{C}$ under the optimal process. In contrast, anticondensation ice fog seal layer with different composition prepared in this paper can reduce the freezing point of pavement water to $-7.6^{\circ} \mathrm{C} \sim-14.2^{\circ} \mathrm{C}$ during the first freezing and can effectively reduce the freezing point of pavement water to a greater extent.

4.3. Antiskid Performance Test. Spraying the anticondensation ice fog seal layer will reduce the antiskid performance of the pavement to a certain extent, and the texture structure between the aggregates will be reduced by being filled with asphalt. The fog seal is used as a preventive maintenance measure, and the recommended spray amount is $0.23-0.45 \mathrm{~L} / \mathrm{m}^{2}$.

According to the specifications, the structural depth of the pavement after spraying the anticondensation ice fog seal layer should be greater than $0.55 \mathrm{~mm}$. Figure 8 shows the attenuation results for the antislip structural depth of the anticondensation ice-melt snow fog seal under different spray rates.

The anticondensation ice-melting and snow-melting fog seal layers reduced the depth of the road surface structure to varying degrees. The antiskid structural depth of the magnesium acetate-encapsulated emulsion did not meet the requirements when the spray amount was $0.5 \mathrm{~L} / \mathrm{m}^{2}$. Considering the antiskid performance and cost, the recommended spray rate is $0.4 \mathrm{~L} / \mathrm{m}^{2}$, and its antislip and antiwear properties meet the specifications and ensure the safety of traffic.

4.4. Durability Evaluation Test. The fog seal layer was sprayed on a test piece at $0.4 \mathrm{~L} / \mathrm{m}^{2}$, and an immersion wheel abrasion tester was used to test the abrasion resistance of anticondensation ice fog seal layer. Three parallel specimens were tested with an average abrasion value of $306 \mathrm{~g} / \mathrm{m}^{2}$. The mass loss before and after the experiment was about $6 \%$, and it was similar to the test results of $\mathrm{Wu}$ et al. as around $5 \sim 8 \%$ 
TABLE 8: Freezing point test results for the anticondensation ice fog seal layer against repeated freeze-thaw cycles $\left({ }^{\circ} \mathrm{C}\right)$.

\begin{tabular}{|c|c|c|c|c|c|c|c|c|}
\hline \multirow{2}{*}{$\begin{array}{l}\text { Matching plan } \\
\text { Proportion of freeze-thaw cycles }\end{array}$} & \multicolumn{4}{|c|}{$\begin{array}{c}\text { Cationic emulsified } \\
\text { asphalt }+ \text { CMC + magnesium acetate }\end{array}$} & \multicolumn{4}{|c|}{$\begin{array}{l}\text { Anionic emulsified asphalt }+ \text { PVA }+ \text { sodium } \\
\text { acetate }\end{array}$} \\
\hline & $2: 1$ & $1: 1$ & $1: 2$ & $1: 3$ & $2: 1$ & $1: 1$ & $1: 2$ & $1: 3$ \\
\hline First cycle & -7.6 & -8.9 & -10.6 & -12.4 & -8.7 & -9.6 & -11.4 & -14.2 \\
\hline Second cycle & -4.2 & -6.5 & -7.5 & -8.9 & -6.2 & -7.7 & -7.9 & -9.3 \\
\hline Third cycle & -1.3 & -3.3 & -5.4 & -5.6 & -3.5 & -4.9 & -5.6 & -6.3 \\
\hline Fourth cycle & 0 & -0.6 & -2.8 & -3.3 & 0 & -2.1 & -3.3 & -3.6 \\
\hline
\end{tabular}

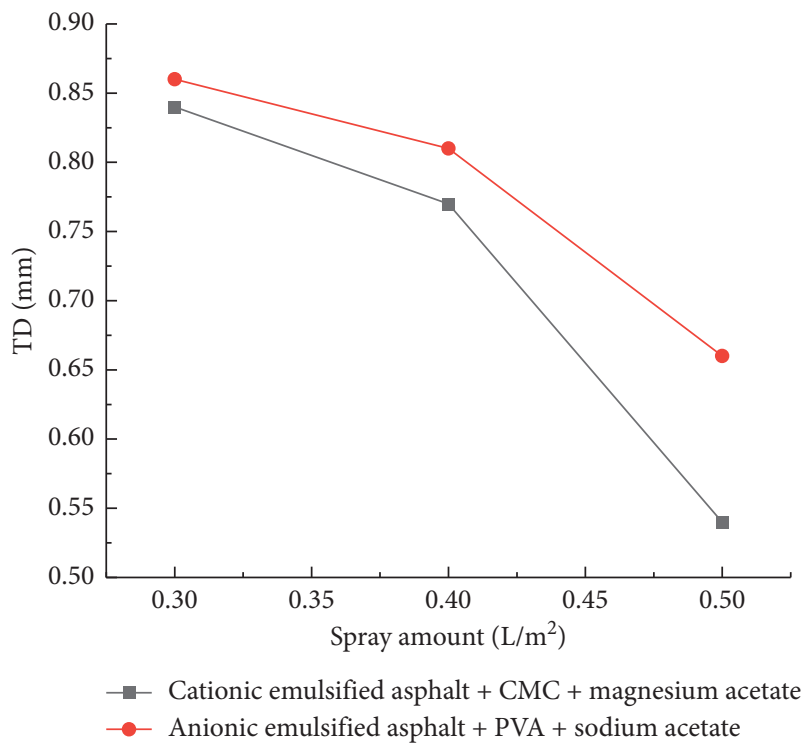

FIGURE 8: Depth of the antisliding structure of anticondensation ice-melting mist seal under different spraying conditions.

[35]. From the test data, it can be seen that the abrasion resistance of the anticondensation ice fog seal met the requirements of the JT/T 1330 specification "Asphalt Pavement Fog Seal Material Emulsified Asphalt Slurry Seal."

\section{Conclusion}

In this study, an anti-icing environmental protection fog seal was prepared by adding a nonchloride salt to emulsified asphalt, and its antiskid performance and durability were tested. The following main conclusions could be drawn:

(1) The encapsulation material allowed the freezing point to be reduced for a long time. The collocation schemes of a cationic emulsified asphalt + CMC + magnesium acetate and an anionic emulsified asphalt + PVA + sodium acetate showed the best stability.

(2) Anionic snow-melting base stock solution has better stability and economy than cationic emulsified asphalt. In practical engineering applications, anionic emulsified asphalt can be given priority.

(3) Pull-out tests showed that fog seal layers applied using different spray rates could reduce the freezing point to at least $-8^{\circ} \mathrm{C}$. When using an anticondensation ice fog seal layer with a snow-melting salt concentration of $18 \%$, the freezing point of the road surface water could still be reduced to $-3^{\circ} \mathrm{C}$ after four freezing and thawing cycles.

(4) The snowmelt fog seal layer reduced the antiskid performance of the road surface. Under the condition of a spraying volume of $0.4 \mathrm{~L} / \mathrm{m}^{2}$, the antiskid performance and durability could still meet the requirements of the specification.

The conclusion shows that spraying the anti-icing fog seal on the road surface can resist the road ice condensation, and the combination of mechanical snow removal can reduce the occurrence of traffic accidents, but the slow release and durability of the anti-icing fog seal need to be further studied. In addition, in order to verify the actual project effect, it is also necessary to conduct on-site testing through the paving test section.

\section{Data Availability}

The data used to support the findings of this study are included within the article.

\section{Conflicts of Interest}

The authors declare no conflicts of interest.

\section{Acknowledgments}

This research was supported by the Basic Scientific Research of Central Institute (2020-9049) and National Key R\&D Program of China (2018YFB1600100).

\section{References}

[1] J. Shi, "Winter ice-melting and snow-removing maintenance technology for expressways in southern mountainous areas," Engineering Construction and Design, vol. 16, pp. 158-159, 2020.

[2] Y. Tan, C. Zhang, H. Xu, and T. Dong, "Research review on the characteristics of active snow and snow melting and road performance," Journal of China Highway, vol. 32, no. 4, pp. 1-17, 2019.

[3] P. Pan, S. Wu, Y. Xiao, and G. Liu, "A review on hydronic asphalt pavement for energy harvesting and snow melting," Renewable and Sustainable Energy Reviews, vol. 48, pp. 624634, 2015.

[4] M. A. Cunningham, E. Snyder, D. Yonkin, M. Ross, and T. Elsen, "Accumulation of deicing salts in soils in an urban environment," Urban Ecosystems, vol. 11, no. 1, pp. 17-31, 2007. 
[5] H. Xu, Y. Tan, Z. Fu, and C. Zhou, "Study on snowmelting performance of road snowmelting system coupled with solar energy and soil source heat energy," Acta Energia Sinica, vol. 32, no. 9, pp. 1391-1396, 2011.

[6] G. Cheng, P. Han, and S. Du, "Overview of snow melting agents and existing problems," Shanxi Transportation Science and Technology, vol. 05, pp. 45-46, 2004.

[7] L. Fay and X. Shi, "Environmental impacts of chemicals for snow and ice control: state of the knowledge," Water, Air, \& Soil Pollution, vol. 223, no. 5, pp. 2751-2770, 2012.

[8] Z. Zhang, S. Du, and S. Zhao, "Research on the impact of snow melting agent on transportation facilities and environment and its countermeasures," Shanxi Architecture, vol. 36, no. 23, pp. 345-347, 2010.

[9] X. Cha, "Research status and progress of snow melting agents," Jiangxi Chemical Industry, vol. 04, pp. 13-15, 2013.

[10] Y. Tan, M. Hou, L. Shan, and R. Sun, "Development of slowrelease complex salt filler for salt storage asphalt pavement," Journal of Building Materials, vol. 17, no. 2, pp. 256-260, 2014.

[11] H. Zhang, W. Pan, and S. Lu, "Indoor test study of saltmelting ice and snow asphalt mixture," China and Foreign Highway, vol. 29, no. 1, pp. 220-222, 2009.

[12] R. Dubois, De-icing compositions contained in road surface material, CH 19730008506, Verglimit Trading Ltd A Corp Of Hong Kong, Hong Kong, China, 1973, https://patents.google. $\mathrm{com} /$ patent/US4012537A/en.

[13] P. L., Preparation and utilize of snowmelt ad mixture for asphalt pavement, Chang'an University, Xi'an, China, 2013, https://patents.google.com/patent/CN102092978B/en.

[14] J. Suren and W. Kamereit, Method and composition for preventing traffic surfaces becoming slippery in winter, US 6982044 (B2), Hexion GmbH, Bengaluru, India, 2006, https:// patents.google.com/patent/US6982044B2/en.

[15] W. Kämereit and A. Boes, Method of producing synthetic gravel and/or chippings containing salt, DE 19924230545, Vodafone GmbH, Düsseldorf, Germany, 1992, https:// patents.google.com/patent/EP0659202A1/en.

[16] X. H. Zhao, X. D. Zhang, Y. J. Meng, and Y. Mei, "Research on the mechanism of melting ice on storage-salt roads," in Proceeding of the 10th International Conference of Chinese Transportation Professionals (ICCTP), Beijing, China, August 2010.

[17] Z. Wang, T. Zhang, M. Shao, T. Ai, and P. Zhao, "Investigation on snow-melting performance of asphalt mixtures incorporating with salt-storage aggregates," Construction and Building Materials, vol. 142, pp. 187-198, 2017.

[18] C. Peng, J. Yu, Z. Zhao et al., "Synthesis and properties of a clean and sustainable deicing additive for asphalt mixture," PloS One, vol. 10, no. 1, Article ID e0115721, 2015.

[19] C. Peng, J. Yu, Z. Zhao et al., "Preparation and properties of a layered double hydroxide deicing additive for asphalt mixture," Cold Regions Science and Technology, vol. 110, pp. 7076, 2015.

[20] H.-G. Eumann and W. Kämereit, Protective layer for the surface of traffic areas and process for applying a protective layer, DE 19934311003, Germany, 1993, https://patents. google.com/patent/WO1994023130A1/en.

[21] H. Dou, Z. Liu, S. Chen, and M. Xing, "Research on the preparation and properties of active sno wmelt emulsion system," Highway, vol. 59, no. 7, pp. 345-349, 2014.

[22] L. M. Young and S. A. Durham, "Performance of an anti-icing epoxy overlay on asphalt surfaces," Journal of Performance of Constructed Facilities, vol. 27, no. 6, pp. 836-840, 2013.
[23] S. Luo and X. Yang, "Performance evaluation of high-elastic asphalt mixture containing deicing agent Mafilon," Construction and Building Materials, vol. 94, pp. 494-501, 2015.

[24] Z. Min, Y. Xia, and X. Li, "Performances evaluation of epoxy asphalt mixture containing snow-melting agent," Construction and Building Materials, vol. 155, pp. 762-769, 2017.

[25] P. Becher, "Journal of dispersion science and technology," in Principles of Colloid and Surface Chemistry, P. C. Hiemenz, Ed., pp. 677-729, Basel Marcel Dekker Inc, New York, 2nd edition, 1986.

[26] R. Chang, Research on Microcapsule Snow Melting Agent and Snow Melting Fog Sealing Layer, Chang'an University, Xi'an, China, 2013.

[27] B.-A. Noskov, S.-Y. Lin, G. Loglio, R. G. Rubio, and R. Miller, "Dilational viscoelasticity of PEO-PPO-PEO triblock copolymer films at the air-water interface in the range of high surface pressures," Langmuir: The ACS Journal of Surfaces and Colloids, vol. 22, no. 6, pp. 2647-2652, 2006.

[28] T. R. Yu, "Chemistry of variable charge soils," OUP Catalogue, vol. 51, no. 3, pp. 541-549, 1997.

[29] V. M. J. Z. P. I. C. Science, "Principles and applications," Journal of Colloid and Interface Science, vol. 88, no. 2, p. 608, 1982.

[30] J. Zhou, J. Li, G. Liu, T. Yang, and Y. Zhao, "Long-term performance and deicing effect of sustained-release snow melting asphalt mixture," Advances in Civil Engineering, vol. 2019, 12 pages, 2019.

[31] Y. Sun, J. Pan, F. Chi, and Z. Guo, "Research on mix design of high viscosity emulsified asphalt sand seal layer," Journal of Shenyang Jianzhu University (Natural Science Edition), vol. 33, no. 4, pp. 637-644, 2017.

[32] H. Du, Y. Wang, and M. He, "Research on the improvement effect of organic retarders on cement modified emulsified asphalt mortar," Materials Review, vol. 33, no. S2, pp. 254260, 2019.

[33] J. Xiao, Study on the Performance of Modified Emulsified Asphalt and Mixture at the Micro-surface, Chang'an University, Xi'an, China, 2007.

[34] M. Yongjun, Z. Qixiong, L. Jiechao et al., "Preparation of biological antifreeze protein-modified emulsified asphalt coating and research on its anti-icing performance," Construction and Building Materials, vol. 294, Article ID 123473, 2021.

[35] S. Wu, J. Yang, X. Sun, C. Wang, R. Yang, and J. Zhu, "Preparation and characterization of anti-freezing asphalt pavement," Construction and Building Materials, vol. 236, no. 6, p. 117579, 2020.

[36] Y. Zhao, Preparation and Performance of Salt Storage SlowRelease Snow-Melting and Ice-Inhibiting Materials, Beijing University of Chemical Technology, Beijing, China, 2020. 